\title{
К ВОПРОСУ ОЦЕНКИ ЭКОНОМИЧЕСКОГО И СОЩИАЛЬНОГО УЩЕРБА ОТ НАВОДНЕНИЙ
}

\author{
Суржиков В.И.
}

Тихоокеанский институт географии ДВО РАН, Владивосток

Владивостокский государственный университет экономики и сервиса, Владивосток Surzhikov.Viktor@gmail.com

Аннотация. В статье приведены результаты анализа работ отечественных авторов, посвященных оценке экономического и социального ущерба, наносимого опасными гидрологическими явлениями (наводнениями). Все методики носят рекомендательный характер. Авторами принимаются во внимание различные факторы, влияющие на размер ущерба. Использование различных критериев, составляющих ущерб, приводит к получению разных цифр. Большинство методик не являются комплексными, не учитывают региональную специфику. Чаще всего определяется только реальный или прогнозный прямой ущерб, в то время как косвенный ущерб не рассчитывается. Преобладают оценки экономического ущерба в связи с ориентацией статистики на учет материальных ценностей. Социальный ущерб от наводнений оценить сложнее. Однако ущерб здоровью пострадавших от наводнений людей представляет не меньшую проблему, чем ущерб экономики. В статье отмечается, что для минимизации негативного воздействия, наносимого опасными гидрологическими явлениями (наводнениями), чрезвычайно важным является определение территорий потенциально подверженных риску наводнений. Выделено три этапа. На первом этапе требуется создание банка гидрометеорологических данных (превышение опасной отметки уровня воды и случаи затопления близлежащего населённого пункта, максимальные уровни, расходы воды, водного режима). На втором этапе производятся гидрологические расчеты, определяются уровни и расходы воды разной процентной обеспеченности. На третьем этапе на основе данных дистанционного зондирования земли строится цифровой рельеф исследуемой территории, изолинии рельефа нужной детальности, карта зон затопления (на основе рассчитанных уровня и расхода воды разной процентной обеспеченности), определяются площади затопления при $1 \%$ и $10 \%$ обеспеченности. Завершающим шагом является добавление таких данных Публичной кадастровой карты, как площадь земельного участка, его кадастровая стоимость и вид разрешенного использования. Используя нормативы укрупненных удельных показателей стоимости прямого ущерба в расчете на 1 га затопляемой площади населенных пунктов, возможно рассчитать прогнозный экономический ущерб. Для расчета прогнозного социального ущерба потребуются данные численности населения, проживающего в прогнозируемых зонах затопления, его половозрастной состав, занятость.

Ключевые слова: оценка, риск, экономический ущерб, социальный ущерб, наводнение. 


\title{
TO THE QUESTION OF ASSESSMENT ECONOMIC AND SOCIAL DAMAGE FROM FLOODING
}

\author{
Surzhikov V.I. \\ Pacific Geographical Institute FEB RAS, Vladivostok \\ Vladivostok State University of Economics and Service, Vladivostok
}

\begin{abstract}
Annotation. The article presents the results of an analysis of the works of domestic authors on the assessment of economic and social damage caused by dangerous hydrological phenomena (floods). All methods are advisory in nature. The authors take into account various factors affecting the amount of damage. The use of various criteria constituting the damage leads to different numbers. Most of the methods are not complex, do not take into account regional specifics. Most often, only real or forecast direct damage is determined, while indirect damage is not calculated. Estimates of economic damage prevail in connection with the orientation of statistics on accounting for material values. Social damage from floods is more difficult to assess. However, the damage to the health of people affected by floods is no less a problem than damage to the economy. The article notes that in order to minimize the negative impact caused by hazardous hydrological events (floods), it is extremely important to identify areas that are potentially at risk of floods. Three stages are distinguished. At the first stage, the creation of a hydrometeorological data bank is required (excess of a dangerous water level mark and cases of flooding of a nearby settlement, maximum levels, water discharge, water regime). At the second stage, hydrological calculations are made, the levels and discharges of water of different interest rates are determined. At the third stage, based on the data of remote sensing of the earth, a digital topography of the study area, contour contours of the required detail, a map of flood zones (based on the calculated level and flow rate of water with different percentage coverage) are built, and the flood areas are determined at $1 \%$ and $10 \%$ coverage. The final step is to add such data of the Public Cadastral Map as the area of the land plot, its cadastral value and type of permitted use. Using the standards of aggregated specific indicators of the cost of direct damage per 1 ha of flooded area of settlements, it is possible to calculate the predicted economic damage. To calculate the predicted social damage, you will need data on the number of people living in the forecasted flood zones, their gender and age composition, and employment.
\end{abstract}

Key words: assessment, risk, economic damage, social damage, flood.

Ежегодно в России происходит не более 100 крупных наводнений различных генетических типов. Однако, по самым скромным оценкам экономический ущерб достигает от 40 до 50 млрд. рублей в год. Для определения наиболее точного размера компенсации ущерба, страховых выплат, а также для разработки комплексных мер по минимизации негативного воздействия опасных гидрологических явлений (наводнений) требуется изучение и совершенствование методов оценки.

Единая методика определения социально-экономического ущерба от наводнений в РФ отсутствует. Использование различных мето- 
дов оценки может привести к неодинаковым результатам. Это усложняет оценку и затрудняет возмещение ущерба, который в зависимости от объекта воздействия может быть:

- медико-биологическим (ущерб жизни и здоровью населению);

- экономическим (утрата того или иного вида собственности, затраты на переселение людей, выплата компенсаций пострадавшим, упущенная выгода от не заключенных и расторгнутых контрактов, нарушение процесса нормальной хозяйственной деятельности, ухудшение условий жизнедеятельности людей и т.д.);

- социально-политическим (ущерб государству);

- экологическим (ущерб природной среде, под которым понимается ухудшение природной среды или затраты на ее восстановление, потеря народнохозяйственной ценности территорий или затраты на ее реабилитацию).

Анализ работ отечественных авторов показал, что в существующих методиках оценки экономического и социального ущерба от наводнений принимаются во внимание различные факторы, влияющие на размер ущерба (табл.).

Обобщая результаты анализа, можно сделать следующие выводы:

- использование различных критериев составляющих ущерб приводит к получению разных цифр даже при оценке одного и того же явления;

- большинство методик не являются комплексными;

- не во всех методиках используется важнейший критерий «длительности стояния паводочных вод»;

- определяется только реальный или прогнозный прямой ущерб, в то время как косвенный ущерб не рассчитывается.

Оценка косвенного экономического ущерба затруднительна в силу сложности его определения (оплата за период простоя, потери на транспорте, упущенная выгода, ущерб, наносимый смывом загрязняющих веществ, доставка в пострадавшие от наводнения районы продуктов питания, одежды, медикаментов, строительных материалов и техники, кормов для скота) и расчета.

Наводнения наносят значительный урон инфраструктуре, сельскому хозяйству, нарушают системы жизнеобеспечения населения, но помимо материального ущерба, вызывают тяжелые морально-психологические и социальные последствия, так называемый социальный ущерб. Оздоровление пострадавших от наводнений лю- 
Факторы, влияющие на размер ущерба от наводнений

\begin{tabular}{|c|c|}
\hline Автор методики & Факторы \\
\hline Алексеев Н.А. [2] & $\begin{array}{l}\text { - Максимальный уровень воды, установленный } \\
\text { во время паводка; } \\
\text { - Длительность стояния паводковых вод; } \\
\text { - Скорость роста расходов воды; } \\
\text { - Частота повторения наводнения; } \\
\text { - Сроки (время) наводнения; }\end{array}$ \\
\hline Авакян А.Б. [1] & $\begin{array}{l}\text { - Площадь затопления; } \\
\text { - Время наступления и окончания наводнения; } \\
\text { - Длительность; } \\
\text { - Скорость подъема уровня воды; } \\
\text { - Обеспеченность паводка или половодья; } \\
\text { - Время добегания волны; } \\
\text { - Наличие защитных сооружений и степень их } \\
\text { надежности; } \\
\text { - Обеспечение точным и своевременным } \\
\text { прогнозом; } \\
\text { - Подготовленность населения; }\end{array}$ \\
\hline $\begin{array}{c}\text { Воробьев Б.В., } \\
\text { Косолапов Л.А. [4] }\end{array}$ & $\begin{array}{l}\text { - Степень хозяйственной освоенности } \\
\text { территории; } \\
\text { - Уровень воды; } \\
\text { - Повторяемость (постоянство) наводнений; } \\
\text { - Времени затопления; } \\
\text { - Продолжительность; } \\
\end{array}$ \\
\hline $\begin{array}{c}\text { Борщ С.В., } \\
\text { Мухин В.М. [3] }\end{array}$ & $\begin{array}{l}\text { - Плотность населения; } \\
\text { - Средневзвешенное по площади региона } \\
\text { значение обеспеченности максимального уровня } \\
\text { воды; }\end{array}$ \\
\hline $\begin{array}{c}\text { Единая межведомственная } \\
\text { методика оценки ущерба... [5] }\end{array}$ & $\begin{array}{l}\text { - Интенсивностью ЧС (модель воздействия); } \\
\text { - Сопротивлением воздействию; }\end{array}$ \\
\hline
\end{tabular}

дей представляет не меньшую проблему, чем восстановление экономики.

Население, перенёсшее стрессовое состояние, вызванное ощущением потери родственников, нажитого имущества, рабочего места, может испытывать даже через длительное время (1-2 года) фобии, тревоги, депрессии, напряженности, возбудимости, соматические расстройства, проявлять социальную изоляцию и изменение модели поведения. У мужской части пострадавшего населения может наблюдаться повышение потребления алкоголя, никотина, у женской - лекарственных препаратов. 
На практике для быстроты оценка ущерба производится силами оценочных комиссий на основании заявлений от пострадавших. В непосредственные обязанности оценочной комиссии входит: определение степени нанесения материального ущерба, причиненного имуществу граждан; проведение обследования поврежденных строений, утраченного урожая сельскохозяйственных культур на приусадебных земельных участках, огородах; гибели домашних животных; проверка сведений и рассмотрение документов, представленных пострадавшими для получения компенсации. Масштабы стихийного бедствия могут замедлить работу оценочной комиссии. Парфенова О.Т. в своей работе по оценке экономического ущерба от наводнений отмечает: «Поскольку в России нет законов, устанавливающих четкие критерии для отнесения имущества к категории «частично» либо «полностью» утраченного, местные власти самостоятельно их ввели. Например, в Ленском районе Республики Саха (Якутия) ущерб определялся по отметке уровня воды. При 100-процентном затоплении (независимо от реального урона) выплачивалось 50 тыс. руб. на семью, а если слой воды составил менее 50 сантиметров, то выдавали лишь тысячу рублей на каждого ее члена. Безусловно, сумма компенсации не соответствует реальному ущербу» [7].

Наводнения как опасные стихийные явления не могут быть полностью предотвращены. Поэтому чрезвычайно важным является определение территорий потенциально подверженных риску наводнений (рис.) и оценка потенциальных экономических и социальных последствий.

На первом этапе требуется создание банка гидрометеорологических данных. Для этого из существующей сети гидрологических постов выбираются те, в которых были зафиксированы превышение опасной отметки уровня воды и случаи затопления близлежащего населённого пункта, определяются максимальные уровни, расходы воды, водного режима.

На втором этапе производятся гидрологические расчеты, главная цель которых -определить уровни и расходы воды разной процентной обеспеченности.

На третьем этапе на основе данных SRTM-4 (Shuttle radar topographic mission) собирается цифровой рельеф исследуемой территории [9]. Затем в любой из существующих геоинформационных систем строятся изолинии рельефа любой детальности, карта зон 


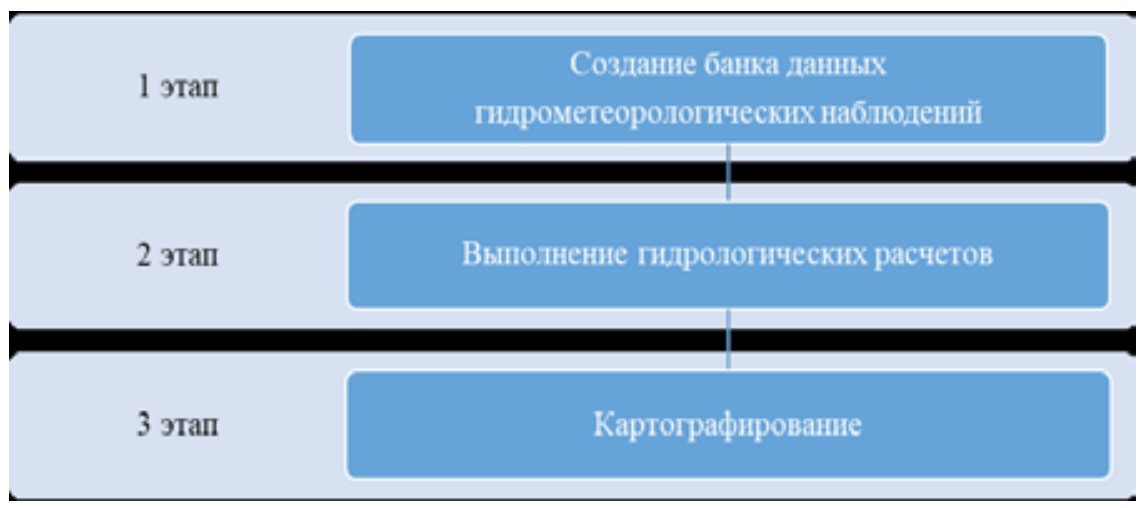

Рис. Этапы определения потенциальной подверженности риску наводнений

затопления (на основе рассчитанных уровня и расхода воды разной процентной обеспеченности), определяются площади затопления при $1 \%$ и $10 \%$ обеспеченности. В первом случае развивается максимально возможный сценарий затопления территории, во втором - начинает затапливаться прибрежная территория. Последним шагом на данном этапе является добавление данных Публичной кадастровой карты: площадь земельного участка, его кадастровая стоимость и вид разрешенного использования [8].

На основе расчетных данных, используя нормативы укрупненных удельных показателей стоимости прямого ущерба в расчете на 1 га затопляемой площади населенных пунктов [6] можно рассчитать прогнозный экономический ущерб. Однако, для расчета прогнозного социального ущерба потребуется набор демографических данных (численность населения, проживающего в прогнозируемых зонах затопления, его половозрастной состав, занятость).

Литература

1. Авакян А.Б. О воде с тревогой и надеждой. Екатеринбург: РосНИИВХ, 1999. $174 \mathrm{c}$.

2. Алексеев Н.А. Стихийные явления в природе: проявление, эффективность защиты. М.: Мысль, 1988. 254 с.

3. Борщ С.В., Мухин В.М. Метод прогноза возможного ущерба от наводнений: на примере Московской области // Метеорология и гидрология. 2000. №7. С. 98-107.

4. Воробьев Б.В., Косолапов Л.А. Водотоки и водоемы: взаимосвязь экологии и экономики. Л.: Гидрометеоиздат, 1987. 267 с. 
5. Единая межведомственная методика оценки ущерба от чрезвычайных ситуаций техногенного, природного и террористического характера, а также классификации и учета чрезвычайных ситуаций. М.: ФГУ ВНИИ ГОЧС (ФЦ), 2004. 57 с.

6. Методические рекомендации по оценке ущерба, вызванного крупномасштабным наводнением в регионах Дальневосточного федерального округа. М., 2014. 17 с.

7. Парфенова О.Т. Оценка экономического ущерба от наводнений на реке Анабар Республики Саха (Якутия) // Вестник СВФУ. Серия Экономика. Социология. Культурология. 2018. №1 (09). С. 37-43.

8. Публичная кадастровая карта Росреестра [Электронный ресурс] // Федеральная служба государственной регистрации, кадастра и картографии (Росреестр). - Режим доступа: https://pkk5.rosreestr.ru/ (дата обращения: 23.06.2019).

9. SRTM Data [Электронный ресурс] // CGIAR - Consortium for Spatial Information. - Режим доступа: http://srtm.csi.cgiar.org/srtmdata/ (дата обращения: 23.06.2019).

\section{References}

1. Avakyan A.B. $O$ vode s trevogoj $i$ nadezhdoj [About water with anxiety and hope]. Ekaterinburg, RosNIIVH publ., 1999. 174 p.

2. Alekseev N.A. Stihijnye yavleniya v prirode: proyavlenie, effektivnost'zashchity [Natural phenomena in nature: manifestation, protection effectiveness]. Moscow, Mysl' Publ., 1988. 254 p.

3. Borshch S.V., Muhin V.M. Metod prognoza vozmozhnogo ushcherba ot navodnenij: na primere Moskovskoj oblasti [A method for predicting possible flood damage: an example of the Moscow region]. Meteorologiya i gidrologiya - Meteorology and hydrology, 2000, no.7, pp. 98-107.

4. Vorob'ev B.V., Kosolapov L.A. Vodotoki i vodoemy: vzaimosvyaz'ekologii i ekono$m i k i$ [Watercourses and ponds: the relationship of ecology and economics]. Leningrad, Gidrometeoizdat Publ., 1987. 267 p.

5. Edinaya mezhvedomstvennaya metodika ocenki ushcherba ot chrezvychajnyh situacij tekhnogennogo, prirodnogo i terroristicheskogo haraktera, a takzhe klassifikacii $i$ ucheta chrezvychajnyh situacij [The unified interdepartmental methodology for assessing damage from emergency situations of anthropogenic, natural and terrorist nature, as well as the classification and accounting of emergency situations]. Moscow, FGU VNII GOCHS (FC), 2004. 57 p.

6. Metodicheskie rekomendacii po ocenke ushcherba, vyzvannogo krupnomasshtabnym navodneniem v regionah Dal'nevostochnogo federal'nogo okruga [Guidelines for assessing damage caused by large-scale flooding in the regions of the Far Eastern Federal District]. Moscow, 2014. 17 p.

7. Parfenova O.T. Ocenka ekonomicheskogo ushcherba ot navodnenij na reke Anabar Respubliki Saha (YAkutiya) [Assessment of economic damage from floods on the Anabar River of the Republic of Sakha (Yakutia)]. Vestnik SVFU. Seriya Ekonomika. Sociologiya. Kul'turologiya - Bulletin of NEFU. Series Economics. Sociology. Culturology, 2018, no. 1 (09), pp. 37-43.

8. Publichnaya kadastrovaya karta Rosreestra [Public cadastral map of Rosreestr]. Available at: https://pkk5.rosreestr.ru/ (accessed 23.06.2019).

9. SRTM Data. CGIAR - Consortium for Spatial Information. Available at: http:// srtm.csi.cgiar.org/srtmdata/ (accessed 20.06.2019). 